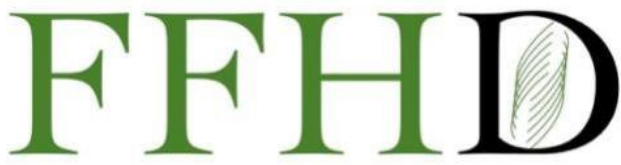

Functional Foods in Health and Disease

\title{
Health communication in nutrition for cancer prevention in Thailand
}

\section{Kamon Chaiyasit $^{1 *}$, Wittayatorn Tokaew ${ }^{1,2}$, Karn Boonsiri ${ }^{1,2}$}

${ }^{1}$ Curriculum of Communication innovation for Political and Local Administration, Sukhothai Thammathirat Open University, Thailand; ${ }^{2}$ Department of Communication Arts, Sukhothai Thammathirat Open University, Thailand

*Corresponding author: Kamon Chaiyasit, Curriculum of Communication innovation for Political and Local Administration, Sukhothai Thammathirat Open University, Thailand

Submission Date: March 16 ${ }^{\text {th }}, 2021$; Acceptance Date: April $7^{\text {th }}, 2021$; Publication Date: April $8^{\text {th }}, 2021$

Please cite this as: Chaiyasit K., Wittayatorn T., Boonsiri K. Health communication in nutrition for cancer prevention in Thailand. Functional Foods in Health and Disease 2021; 11(4): 157-153. DOI: https://www.doi.org/10.31989/ffhd.v11i4.792

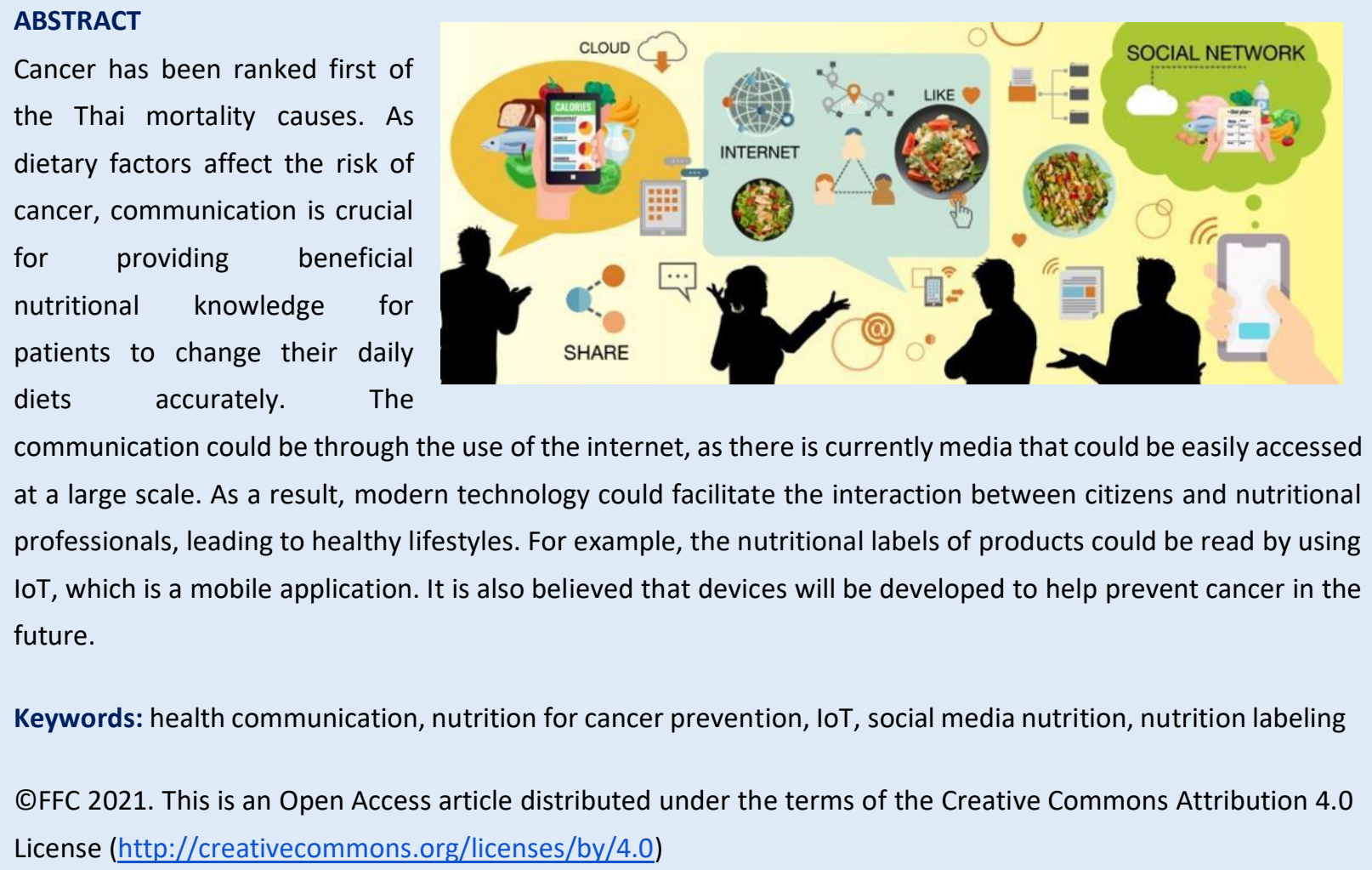

communication could be through the use of the internet, as there is currently media that could be easily accessed at a large scale. As a result, modern technology could facilitate the interaction between citizens and nutritional professionals, leading to healthy lifestyles. For example, the nutritional labels of products could be read by using IoT, which is a mobile application. It is also believed that devices will be developed to help prevent cancer in the future.

Keywords: health communication, nutrition for cancer prevention, loT, social media nutrition, nutrition labeling CFFC 2021. This is an Open Access article distributed under the terms of the Creative Commons Attribution 4.0 License (http://creativecommons.org/licenses/by/4.0) 


\section{INTRODUCTION}

One of the most essential processes for a human's daily life is communication. As a result, there are lots of developments to improve and adapt for many applications. The main example here would be medicines, with the process called "health communication," that is necessary for health professionals to transfer useful medical messages to their patients to gain a better understanding and alter their healthy lifestyles [1].

Nowadays, people across the world focus on the prevention of cancer, as it is a common cause of mortality and has an expensive cost of treatment [2] It is believed that there are various factors of the disease including diets, chemicals, viruses, and genetics [3]. As some types of cancer are related to food, such as gastrointestinal cancer, eating unhealthy food could increase the possibility ofgetting cancer. Consequently, one of the easiest prevention methods is to manage nutritional habits.

The American Cancer Society published a guideline called Diet and Physical Activity for Cancer Prevention in 2020. The guideline suggestscontrolling one's weight and getting all necessary nutrients by eating healthy food, including multiple- colored vegetables and fruits. Moreover, people should avoid drinking fruit squash because it contains too much sugar. It is also essential to avoid refined grains, red meats, and processed food. Furthermore, alcohol consumption should be avoided [4]. This guideline is different from the old one, which stated that 1 drink a day is acceptable. However, it is now believed that refusing to drink is the best thing to do. The Expected Cancer Incidence attributable to alcohol consumption in Thailand in 2021 found out that although alcohol campaigns could not trigger heavy drinkers to stop, it could reduce the number of new drinkers [5].
Thailand's cancer mortality rate is projected to continuously increase. According to the Strategy and Planning Division, Ministry of Public Health, there were approximately 112.8 cancer deaths per thousand of the population in 2015 , and 125 cases per thousand in 2019 [6]. Thai citizens excessively drink alcohol and insufficiently consume the suggested amount of vegetables from the National Cancer Institute guideline composed by Economic Intelligence Center (EIC) of Siam Commercial Bank. Although the survey found that $98.8 \%$ of the Thai population currently eats fruits and vegetables at least once a week, this percentage is shockingly $13.4 \%$ lower compared to 2013 [7]. This decrease is attributed to Thai preferences for generally unhealthy foods. Furthermore, this change is also a result of food influencers who use social media as a platform to impact food choices, encouraging others to consume less fruits and vegetables and more convenience foods that offer little nutrition, leading to a higher risk of cancer.

Nutrition and health communication: Communication is a vital process of message transmission, which includes sender, message, channel, and receiver. The sent messages sometimes need to be encoded or translated. For example, medical translations are essential for patients to understand medical messages. As a result, it could be concluded that health communication is a fusion of communication and medicines used to enhance health. Communication in cancer is often through the use of mass media such as brochures, health magazines, and manuals. However, people access 
various modern media, so most of the health information can be received through the Internet on platforms such as Facebook, Line, Twitter, or YouTube [8].

Thai nutritional labels only indicate the nutritive value of the products. Moreover, Guideline Daily Amounts (GDA) improved by THAI FDA (Electronic Transactions Development Agency. Ministry of Digital Economy and Society, 2019) have allowed consumers to check for the presence of specific nutrients in a product and to make an informed food choice. Afterward, entrepreneurs use nutritional logos for their products in order to represent healthy products, which also helps consumers make decisions. For instance, ready-to-eat meals could be approved by considering eight nutrients, including: 1. Fats 2. Saturated fats 3. Protein 4. Fiber 5. Sugars 6. Sodium

7. Calcium 8. Iron. The products should not contain too many nutrients that can provoke the risk of noncommunicable diseases (NCDs). When it comes to drinks, the amount of sugar and fats should be considered to display the Healthier choice logo in Figure 1. However, there are not any Thai labels or logos that represent functional food for cancer prevention or phytochemical ingredients for cancer prevention.
According to the nutritional label knowledge survey by students from public health programs, people are interested in the expiration date of the products, while the harmful ingredients (Monosodium glutamate, sugar amount, etc.) are details that few people pay attention to. Few of them are informed about nutrition labeling, serving size, and recommended dietary allowance [9].

The Communication on social media: Nowadays, everyone is allowed to communicate with one another by the means of smartphones and the Internet, which also affects health information in social media [10]. Based on Thai Internet behavior in 2019, Thai users spent 10 hours and 5 minutes a day on average on the Internet, which increased every year. It also reports that YouTube, Line, and Facebook are the top three media platforms used by Thai. This provokes citizens to learn health information from social media instead of books. Somporn, Meekruea, and Sam-Ang Seubsman reported that health magazines could not trigger people to realize the advantages of fruits and vegetables [11]. Therefore, people's increasing access to social media platforms has caused the Internet to become a vital part for altering eating behavior.

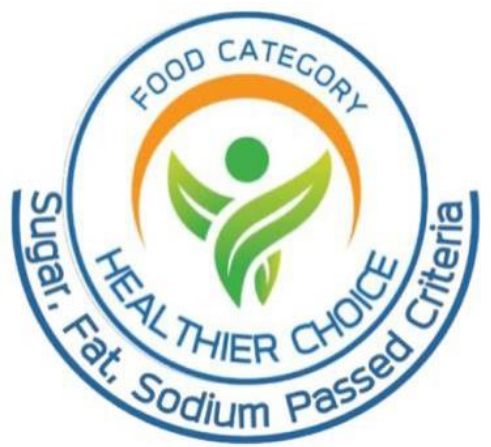

Figure 1. Healthier choice logo from Thai FDA. This logo will display on label of product which pass the Thai FDA criteria low sugar, low sodium, or low fat. 
Social media is the new media communication, as it currently allows a sender to create and send a message and receive feedback from the receiver immediately and conveniently through the use of online devices. It is also beneficial for sharing and exchanging ideas with one another, leading to a network connection [12]. This could encourage people to change their attitudes and behaviors. Social media can be used as a tool for a health promotion campaign. For example, the initiative to encourage intake of 400 grams per day of fruits and vegetables was created by the means of the Internet to make people realize and abide by the recommendations of the Minister of Public Health of Thailand. Innovation diffusion theory can be used for news and innovation communication to the target groups, taking into account their readiness to receive and apply the information. The recipients can be categorized by their ability to perceive messages into 5 groups, including Innovator, Early adopter, Early majority, Late majority, and Laggard. Furthermore, it is necessary to design the message to be suitable for each group of recipients [13].

Nutritional advice for cancer prevention is to eat more than 400 grams of fruit and to avoid alcohol, grilled food, and red meat [14]. Although senders make an effort to send the messages to the receivers, the recipients have difficulty in knowledge translation. For instance, 400 grams of vegetables is difficult for receivers to estimate. Based on the 63 office workers survey in Bangkok, they have little knowledge about cancer prevention. Although they know basic cooking, they misunderstand that fiber powder and antioxidant supplement could prevent cancer. As a result, they could not apply the knowledge in their daily lives.

Numerous online social medias mainly contain information about food for cancer patients, while the details about cancer prevention commonly located in NCDs don't get much attention. Furthermore, the Ministry of Digital Economy and Society of Thailand created an anti-fake news center to reduce misinformation about food and cancer and to cooperate with the ministry of public health to provide accurate health news on social media. Although there is currently little specific information about food for cancer prevention, citizens could be given details about healthy food as guidelines to follow. Since Thai citizens mostly get their information via the Internet, designing the information to be viral, interesting, and applicable could effectively promote foods that help to prevent cancer.

Adaptive technology applications in nutritional communication: Nowadays, technology facilitates healthcare communication in many ways. For example, Big Data systematically analyzes and processes data sets. Furthermore, lots of technologies improve health services, such as Telemedicine for giving advice and the Internet of things (IoT) [15]. As a result, technology gives nutritional advice through devices and applications (apps) that offer nutritional facts of products by scanning barcodes [16]. For example, the Ministry of Public Health's Food Choice application, which can be installed on both Android and iOS, scans QR codes of food products and relays their nutrition, calories, and sugar, helping others to mindfully eat.

In response to the lack of apps that promote foods for cancer prevention, developers have created new applications such as MyFitnessPal, but they come with some limitations [17]. IoT began to apply pictures and image processing with Smart Nutrition Monitoring sentence, which is a database that provides information about photographed food, offering the type and amount of each ingredient [19]. 
The processing of IoT in nutrition calculation is displayed in Figure 2. In 2010, Tambe, Nerkar, Chorage, Dokhe, and Shinde revealed that this system helps people to both control their weight with the advice of Big Data and records the consumption of its users, eventually sending this information to health professionals in the future
[17]. While medical oncologists were more interested in precision medicine in 2015, Intel and The Oregon Health and Science University launched a joint project called the Collaborative Cancer Cloud that considers patients' genes to determine the most effective medicines and treatments.

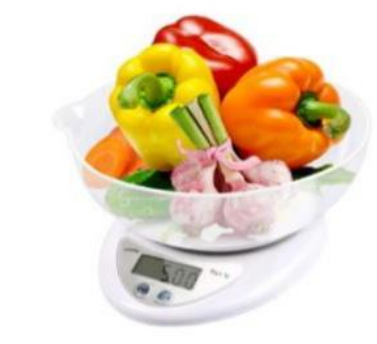

Weighing Sensor

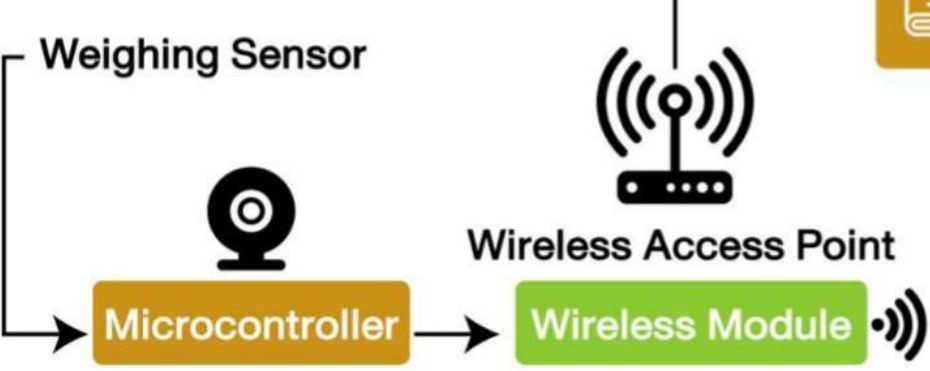

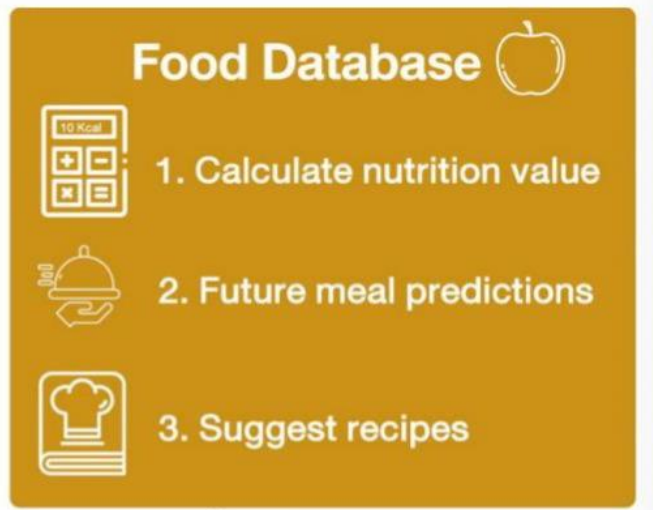

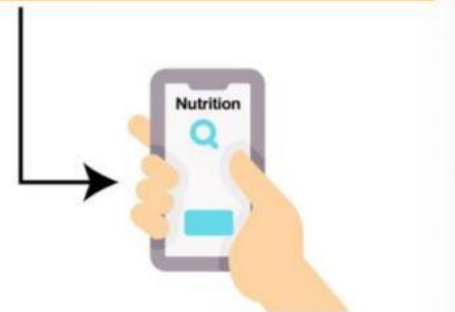

Figure 2. The process of IoT process for analyzing nutrition value from cloud database. This picture is adopted from Sundaravadivel, P., Kavya Kesavan, L. Kesavan, Saraju P. Mohanty and E. Kougianos. "Smart-Log: A Deep-Learning Based Automated Nutrition Monitoring System in the IoT." IEEE Transactions on Consumer Electronics 2018, 390-398.[18]

Expansion of future genetic collection of a population could also make suggestions about cancer prevention foods. In Thailand, these genetic databases could give useful advice for advising on genetic profiles that are quite different in different parts of the country [20].

IOT's analysis of nutrients will help determine the functional foods that prevent cancer, while also helping physicians determine the nutrients that increase the risk of cancer.

\section{CONCLUSION}

Health communication is an essential process used as a means of health promotion as well as the modification of health behavior to achieve thedesired health prevention result. In Thailand, cancer is the number one leading cause of death, however, many types of cancers are preventable through the consumption of certain types of foods. Behavior modification for cancer prevention requires knowledge and communication technologies to help change behaviors. This becomes increasingly important as social media infiltrates lifestyle habits across the globe. 
Therefore, the design of nutrition knowledge diffusion for cancer prevention must be adjusted according to the media consumption behavior of the people and the technologies that play important roles in their ways of life, such as the use of smartphones with various applications to support the needs of users. As a result, nutritional knowledge is integrated with communication, and various technologies, inspiring the development of an IoT that reads the nutritional information from food images and provides recommendations for consumption. By combining nutritional and cancer prevention knowledge with IoT, applications that offer food recommendations will become an important tool for mitigating the risk of cancer.

List of abbreviation: FDA: Food and drug administration, NCDs: Noncommunicable diseases, IOT: Internet of things

Competing Interests: The authors have no financial interests or conflicts of interest.

Authors' contributions: All authors contributed to this study.

Acknowledgment and Funding: The authors declare no acknowledgments or funding.

\section{REFERENCES}

1. Ratzan SC, Payne JG and Bishop C. The Status and scope of health communication. Journal of Health Communication 1996, 1(1):25-41.

2. Zaorsky NG, Churilla TM, Egleston BL, Fisher SG, Ridge JA, Horwitz EM, Meyer JE. Causes of death among cancer patients. Ann Oncol 2017, 28(2):400-407.

3. Rihab Ksouri, Food components and diet habits: chief factors of cancer development, Food Quality and Safety 2019, 3(4):227-231.
4. American Cancer Society. American Cancer Society Guideline for Diet and Physical Activity for Cancer Prevention. A Cancer Journal for Clinicians 2020. 1-31.

5. Virani $S$, Tanaree $P$, Vichitkunakorn $P$, Sriplung $H$, Assanangkornchai S. Expected Cancer Incidence attributable to alcohol consumption in Thailand 2021. Final report. Bangkok: Thailand. Epidemiology Unit Faculty of Medicine Prince of Songkhla University, Thai Health Promotion Foundation and Center for Alcohol Studies; 2018 December. Report No.: A1-0014.

6. Strategy and Planning Division, Ministry of Public Health. Public Health Statistics A.D.2019. [cited 24 December 2020]. Available from: http://bps.moph.go.th/new_bps/sites/default/files/sta tistic62.pdf

7. Thai Health Promotion Foundation. Thaihealth Watch 2020. [cited 24 December 2020]. Available from: https://resourcecenter.thaihealth.or.th/files/90/จับตา\% 2010\%20พฤติกรรมสุขภาพคนไทย\%20ปี\%2063.pdf

8. Moorhead S, Hazlett D, Harrison L, Carroll J, Irwin A, Hoving C. A New Dimension of Health Care: Systematic Review of the Uses, Benefits, and Limitations of Social Media for Health Communication. J Med Internet Res 2013, 15(4):1-75

9. Komwong $D$, Sitthiboot $U$ and Thainua P. Perception and use of food label information among students of Sirindhorn College of Public Health, Chonburi province. Thai Pharm Health Sci 2014, 9(2):39-46

10. Boyd DM, Ellison NB. Social network sites: Definition, history, and scholarship. J Comp Med Commun 2008, $13: 210-230$

11. Meekruea S, Suebsman S and Sleigh A. Perception and awareness of fruit and vegetable benefit messages in health magazine, and fruit and vegetable consumption behavior among Sukhothai thannathirat open university students. Journal of Safety and Health 2015, 8(29): 2735.

12. Fawkes J and Gregory A. Applying communication theories to the internet. Journal of communication management 2000, 5(2):109-124.

13. Kaminski J. Diffusion of Innovation Theory. Canadian Journal of Nursing Informatics 2011, 6(2): 1444-5.

14. Veer P, Jansen MC, Klerk M, Kok FJ. Fruits and vegetables in the prevention of cancer and cardiovascular disease. Public Health Nutr. 2000, $3(1): 103-7$

15. Henderson K, Davis TC, Smith M, King M. Nurse practitioners in telehealth: bridging the gaps in 
healthcare delivery. J Nurse Pract. 2014, 10(10):845850.

16. Franco RZ, Fallaize R, Lovegrove JA, Hwang F. Popular Nutrition-Related Mobile Apps: A Feature Assessment. JMIR Mhealth Uhealth. 2016, 4(3):e85. doi: 10.2196/mhealth.5846. PMID: 27480144; PMCID: PMC4985610.

17. Tambe HK, Nerkar S, Chorage S, Dokhe S, Shinde S. Smart Nutrition Monitoring System. IJRASET 2019, 7(12):404-406.

18. Sundaravadivel, P., Kavya Kesavan, L. Kesavan, Saraju P. Mohanty and E. Kougianos. "Smart-Log: A Deep-
Learning Based Automated Nutrition Monitoring System in the IOT." IEEE Transactions on Consumer Electronics 2018, 390-398.

19. Bouzembrak $Y$, Kluche $M$, Gavai $A$ and Marvin $H$. Internet of Things in food safety: Literature review and a bibliometric analysis. Trends in Food Science \& Technology 2019, 94:54-64.

20. Dimitrov DV. Medical Internet of Things and Big Data in Healthcare. Healthc Inform Res. 2016, 22(3):156-63. 